\title{
Emoção como signo dos espaços em meios de hospedagem
}

Emotion as sign of spaces in hotel facilities

Emoción en el signo de espacios en las instalaciones del hotel

http://dx.doi.org/10.18472/cvt.17n1.2017.1042

Luciano Torres Tricárico 〈lttorres@usp.br >

Universidade do Vale do Itajaí (Univali), Balneário Camboriú, SC, Brasil.

Mônica Santanna de Vargas 〈monicavargastur@gmail.com >

Universidade do Vale do Itajaí (Univali), Balneário Camboriú, SC, Brasil.

CRONOLOGIA DO PROCESSO EDITORIAL

Recebimento do artigo: 02-abr-2015

Aceite: 06-dez-2016

FORMATO PARA CITAÇÃO DESTE ARTIGO

TRICÁRICO, L. T.; VARGAS, M. S DE. Emoção como signo dos espaços em meios de hospedagem.

Caderno Virtual de Turismo. Rio de Janeiro, v. 17, n. 1, p. 46-57, abr. 2017.

REALIZAÇÃO

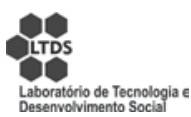

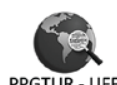

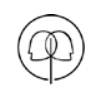

IABS
APOIO INSTITUCIONAL

COPPE

UFR]

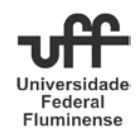

EDIÇÃO

PATROCÍNIO

IR⿴囗十口:

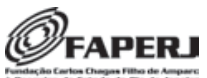




\section{RESUMO}

O objetivo desta pesquisa é sistematizar a emoção como categoria de análise da arquitetura contemporânea, construída potencial e hipoteticamente a partir da arquitetura hoteleira. Para tanto, a pesquisa se caracterizou como exploratória, respaldada pelo levantamento e leitura bibliográficos, bem como estudos de caso e análises empíricas; o método interpretativo foi amparado pela lógica da abdução nos termos de uma semiótica peirceana. Os resultados inferem sobre a possibilidade da emoção como categoria de análise da arquitetura contemporânea, dita também (por muitos) como pós-moderna; superando-se generalizações racionalistas funcionais de sua predecessora arquitetura moderna.

Palavras-chave: Hotel. Emoção. Espaço

\section{ABSTRACT}

The objective of this research is to systematize the emotion as a category of analysis of contemporary architecture, constructed potentially and hypothetically from the hotel architecture. For this purpose, the research is characterized as exploratory, supported by bibliographic survey, as well as case studies and empirical analysis; the interpretive method was supported by the logic of abduction under a Peircean semiotics. The results infer the possibility of emotion as a category of analysis of contemporary architecture, also said (by many) as postmodern; by overcoming functional rationalist generalizations of its predecessor, the modern architecture.

Keywords: Hotel. Emotion. Space.

\section{RESUMEN}

El objetivo de esta investigación es sistematizar la emoción como una categoría de análisis de la arquitectura contemporánea, construida otencialmente y hipotéticamente desde la arquitectura del hotel. Por lo tanto, la investigación se caracteriza como exploratoria, con el apoyo de lectura y revisión bibliográfica, así como estudios de casos y análisis empíricos; el método interpretativo fue apoyado por la lógica de la abducción de acuerdo com la semiótica de Peirce. Los resultados deducen la posibilidad de la emoción como una categoría de análisis de la arquitectura contemporánea, dijo también (por muchos) como posmoderna; mediante la superación de las generalizaciones racionalistas funcionales de su predecesora, la arquitectura moderna.

Palavras clave: Hotel. Emoción. Espacio. 


\section{Introdução}

O mundo contemporâneo se encontra em um novo contexto agora denominado por muitos como próprio de uma era pós-moderna; de modo que se justifica a emoção, em termos genéricos, por um novo padrão demográfico amparado pela crescente melhoria da qualidade de vida e condições mais favoráveis de vida; seja pelas conquistas na saúde pública, seja pelas condições do trabalho, seja pela aposentadoria, entre outras. Isso tudo se reverte para a hotelaria como um meio de hospedagem melhor "desenhado" não só em termos de conforto, mas em termos estéticos, eficiência operacional e "harmonia" ambiental com o local e a comunidade onde se insere (DIAS, 1990). De sorte que tais situações descritas acima podem ser sistematizadas em emoção, sustentabilidade e automação dos espaços em hotéis. Caberá aqui uma "varredura" da condição de emoção na hotelaria; e verificar que ela não é um dado essencialmente contemporâneo; denotando, portanto, que ela foi "subjugada" em sua construção teórica por um viés racionalizante da modernidade e, por "extensão", da arquitetura moderna.

De outra maneira, mas também de modo generalizante, vive-se um "novo" turismo, pós-massificado e com valores que tocam no emocional enquanto solidariedade e afetividade (turismo cultural e de base comunitária, por exemplo); e na busca de densas experiências pessoais, abandonando-se uma racionalidade cerebral, e que agora vincula valores emotivos do "coração" (PETROCCHI, 2002); nesse sentido, a hotelaria como parte efetiva da cadeia turística, não poderia deixar de assim se manifestar. E talvez seja ela uma das que mais podem exemplificar essa condição do turismo atual. A edificação hoteleira passa a estabelecer um vínculo com o desenho e a cultura material e simbólica. Tal arquitetura (e incluam-se o design de objetos do cotidiano e o mobiliário) opera, por vezes, enquanto valor simbólico, como morfologia abstrata muito próxima à fruição de uma obra de arte e de experiências estéticas (MONTANER apud SPOLON, 2011).

Entende-se a emoção não só como uma experiência receptiva do corpo (nos termos de uma fenomenologia de Maurice Merleau-Ponty), mas como uma construção conjunta do corpo como "porta" receptiva e sensorial, dos sentimentos e da mente como judicação simultaneamente integrados. Para tanto, serve-se das teorias de $\mathrm{Yu}$-Fu-Tuan que podem interpretar a emoção como sendo uma combinação de pontos de vista objetivos e subjetivos que têm lugar no "olho da mente". Parece conveniente uma exemplificação lembrada por Kant para se chegar a uma experiência estética como resultante de tal combinação enquanto realização da experiência do sublime. Para Kant, ao se vislumbrar um castelo e julgá-lo como "bonito", está-se fazendo um "juízo de gosto", porém, caso se saiba que esse mesmo castelo foi feito com trabalho escravo, pode-se chegar a uma judicação, dependendo do intérprete visual desse castelo, em que ele deixa de ser "bonito" e "belo", porque incrementou um juízo ético acerca de como foi construído - trata-se, nesse caso, de um "juízo estético" - como aporte de fundamentação que pode demonstrar que a realização da emoção "aprazível" também passa por uma intelecção e construção mental. A "provocação" da mente ao organizar um "juízo estético" pode aguçar o nível repertorial do leitor, sua satisfação em concluir um juízo que lhe é mais adequado, o que não deixa de ser uma fonte de "prazer" "estético", inferindo, portanto, uma hospitalidade dos "mecanismos" mentais de judicação.

Há uma literatura especializada em arquitetura contemporânea que assinala o valor da emoção manifestada espacialmente: "O projeto abrange as qualidades do objeto (forma, proporção, materialidade, composição, etc.), mas inclui qualidades atinentes à sensibilidade (...)” (SOMOL; WHITING apud SYKES, 2013). 
Sabe-se que a condição de um turista, e, portanto, de hóspede, muitas vezes, fora das suas condições cotidianas, alteram formas de agir, manifestando felicidade e até arrogância, ou seja, quebrando comportamentos usuais; o que se pode inferir que tal situação também se constrói pela influência do meio e do suporte espacial, que, no caso estudado, são os hotéis.

Parte-se da leitura do espaço e sua representação (fotografias e vídeos dos espaços de hotéis divulgados em sítios eletrônicos) na tentativa de novas hipóteses. Por se tratar de sistema espacial, é notória sua plurissignificação inerente, originando uma gama de interpretações com várias possibilidades relacionais. Deve-se considerar que o método não se inicia com a formulação de uma teoria que é aplicada ao objeto no intuito de deduzir alguma relação teórica; mas, parte-se do objeto representado como gerador de novas interpretações. O percurso metodológico, ao "encarar" a bibliografia, deu-se com os objetivos de se elencar as diversas formas de emoção à hotelaria, sistematizar e classificar todo esse aporte elencado, interpretar tal sistematização à luz de identificar padrões até então não efetivamente reconhecidos por essa bibliografia levantada.

\section{Emoção do espaço em meios de hospedagem}

Justifica-se a emoção pelos aspectos físicos do espaço hoteleiro: alguns autores se referem à estética de um hotel como a "aparência física do produto, o que se sente com ele, qual o seu som, sabor e cheiro" (GARVIN apud CASTELLI, 2000, p. 29, grifo do autor).

A emoção a partir do meio de hospedagem também pode ser explicada pela psicologia por meio da "experiência" ou da "transferência". No primeiro caso, as afirmações de Yi-Fu Tuan entre as diferentes categorias de espaço e lugar que poderiam ser atribuídas na análise dos edifícios hoteleiros. Os diversos suportes espaciais de um hotel podem construir o ideal de lugar memorável (inclusive para cidadãos locais) porque se relacionam com códigos sociais de marcação do tempo da vida; assim, por exemplo, um ballroom do hotel pode ser o amparo para a festa de batismo, de aniversários, casamentos e bodas. Outro caso da "transferência" mental, por exemplo, é verificar o fato de um hóspede que ao entrar em seu quarto de hotel pode se emocionar pela recorrência da mobília ou decoração em evocar sentimentos de situações pretéritas de ambientes semelhantes.

\section{Home way from home na hotelaria}

O aclamado hoteleiro Cesar Ritz se refere a seus hotéis como "uma casa a qual me orgulho muito de ver meu nome agregado" (DIAS, 2002, p.116). E até há pouco tempo havia uma discussão de que a hotelaria trabalharia com o ideal de home way from home, como que o meio de hospedagem deveria "reproduzir" o pretenso conforto e o bem-estar evocativos do lar daquele hóspede; daí todas as iniciativas de personalização dos ambientes de hotel, bem como um atendimento e serviços destituídos de uma hospitalidade "universalizante". Nesse ideal, há uma busca por "sentir-se em casa, mesmo fora de casa", ou o fato de que "ficar em casa é muito gostoso", daí o intento da hotelaria em reproduzir o lar, afinado com um turismo doméstico que muitas vezes é ignorado ou pouco evidenciado.

Mas se deve interpretar também que esse ideal do home way from home foi uma vertente que o "produto" operou para atendimento de uma determinada segmentação; em uma tentativa de "economizar" o dinheiro do hóspede, reduziram-se facilidades extraunidade habitacional (non-room) e a supressão de 
áreas coletivas tanto o quanto possível, mas que, por outro lado, implicaria em facilidades do tipo "faça você mesmo" como opção no interior das unidades habitacionais (DIAS, 1990). Até mesmo os grandes hotéis tipo towers, que não podiam dar um atendimento personificado para todos os seus hóspedes, reservavam um setor, uma ala, um andar, unidades habitacionais ou suítes que oferecessem um serviço de hotel de família (DIAS, 1990). Um exemplo desse tipo de hotel é, segundo Dias (1990), o Nob Hill Launbourne, localizado em São Francisco, EUA onde as unidades habitacionais são decoradas tentando reproduzir um ideal de lar: motivos campestres franceses aliados à fina mobília, obras artísticas originais, acolchoados de pluma de ganso, cozinha equipada com porcelanas e toalhas de linho, bem como o uso da tecnologia para o hóspede de negócio muito bem integrada à arquitetura de interiores em um home office: "ilha de trabalho" com escrivaninha para computador pessoal, aparelhos de fax, linha telefônica própria da suíte, serviços de tradução e transcrição, impressão, fotocópia e softwares à disposição. Cada computador da unidade habitacional está equipado com informações importantes e de diversões na cidade.

Outro exemplo é o Marriott Residence Inn, em Houston, EUA, onde seus estúdios (associação do quarto de hotel com escritório) promovem a "imagem" do lar: ornamentos requintados, uso do bay window e lareiras "reais" como símbolo do "lar" norte-americano. Tudo isso contando concomitante também com tecnologia aplicada: fornos micro-ondas, refrigeradores, aparelhos de som de última geração, equipamentos para lavar e passar roupas, equipamentos para aquecimento de toalhas de banho, jatos de água com comandos eletrônicos na banheira e chuveiro (DIAS, 1990). Ainda se pode exemplificar os hotéis Mansion on Turtle Creek em Dallas e o L'Ermitage em Bervely Hills, EUA, com maior personificação do espaço interior, um único andar como uma única unidade habitacional, dotado de concierge e elevador privativo (DONZEL, 1989).

Do mesmo modo puderam se destacar a cadeia de hotéis Four Seasons por meio da metáfora da "casa longe de casa" e que abrigou grandes chefes de Estado, personalidades mundiais, a aristocracia e até mesmo a realeza $(\mathrm{CHON}, 2003)$.

A designer de hotelaria Sarah Tomerlin Lee se destacou no seu meio profissional por criar um estilo próprio o qual não era "reconhecido" como "seu". Sarah acreditava que o que devia vir primeiro não era o projeto dos espaços do hotel, mas para "quem" era feito o projeto; respeitando as expectativas do hóspede (CHON, 2003).

Chon (2003) acusa uma tendência da hotelaria na utilização de mobília de estilos residenciais, seja em hotéis novos ou reformados, bem como interpreta que as pousadas devem oferecer uma "atmosfera aconchegante", tal qual uma casa; ali, cafés da manhã comunitários entre hóspedes e anfitriões podem enfatizar essa sensação (CHON, 2003).

\section{Além do home way from home na hotelaria}

Diz-se que o home way from home na hotelaria já não mais "retrata" o que realmente os hóspedes desejam; eles "[...] querem mais do que habitualmente teriam em seus lares" (WADA, 2003, p. 70). Pode-se notar uma gama de manifestações da hotelaria contemporânea que vão além do ideal de "reconstrução" do "lar" como busca do bem-estar de seus hóspedes. O hotel deve ser algo tão mais emocionante do que a vivência do que já se apreende no cotidiano. Os serviços hoteleiros carregam agora a responsabilidade de serviços pessoais (DIAS, 1990). Benevides (CRUZ apud DIAS, 2002) se refere a uma das maiores motivações da demanda de turismo tradicional e de massa como a viagem para "não se sentir em casa"; 
associa-se ainda o fato de que a hospitalidade possui ingredientes de espontaneidade e artificialidade que se combinam, e muitas vezes não são fruídas em espaços codificados como o "lar". Esses espaços de hotéis podem ser entendidos não essencialmente como uma manifestação contemporânea, pois o ideal do "grande hotel americano", já nos primórdios do século XIX (concomitante com a cultura norte-americana de passar as férias longe de casa), anunciava a "fantasia" a partir de suas espacialidades (diferentes das concepções da hotelaria europeia até então), as celebrações que encerravam para "todos", ainda que muitos não pudessem "passar" uma noite por lá, em razão dos altos custos das estadas (DONZEL, 1989): "Em todos esses lugares [...] a vida é vivida não como todos os dias, mas, como é vislumbrada, com o drama e a surpresa, com a beleza física [...] com um sentimento de cuidado [...]" (DONZEL, 1989, p. 9; tradução livre).

Atualmente essa cultura do grande hotel norte-americano em oferecer o escapismo "fantasioso" se prolongou no Caesar's Palace de Las Vegas, por exemplo, onde há porteiros com togas romanas, a "barca de Cleópatra" flutuando em espelhos d'água junto a corredores, unidades habitacionais com tetos espelhados e banheiras em forma de coração. No Disneyland Hotel a fantasia é completa e atinge pais e filhos (DONZEL, 1989).

Nesse sentido também, a linha dos hotéis Hyatt é vista por muitos arquitetos como "surrealista", com espaços fora da vida real (DIAS, 2002). A sensação de uma "projeção" do modo de vida aristocrático e da nobreza por parte de muitas pessoas encontrou nos châteaux (meio de hospedagem em um castelo, mansão senhorial ou palácio) a concretização dessa experiência. Dessa forma, ficou conhecido o Châteux Hôtel de Rieutort, no sul da França, ou o Châteux de Roussan na Provence, também na França. São dotados de camas ornamentadas, jardins internos, construções seculares como apreensão de uma experiência histórica e o contato com os anfitriões (geralmente de famílias nobres e aristocráticas). Da mesma forma, os paradores na Espanha podem proporcionar a divulgação e conhecimento da história do país através de edificações de interesse patrimonial artístico-arquitetônico. São os casos de antigos conventos (como o Parador de Trujillo) e antigos palácios (como o Parador de Argomaniz) (CHON, 2003).

Acampamentos de finais de semana, muitas vezes vinculados às áreas periurbanas ou rurais, podem proporcionar o contato recreativo ao ar livre, bem como a prática de esportes (DIAS, 1990) e atividades de caça e pesca. Os ecolodges se sustentam na apropriação do deleite do destino enquanto natureza, mas também podem incluir aspectos relacionados à cultura, como sítios arqueológicos, monumentos históricos, lendas, tradições e artesanato (KOGA, 2002). Nesse sentido, mas enquanto outra categoria de meio de hospedagem, o ideal do Club Med é poder proporcionar ao hóspede a prática de esportes inusitados, os quais muitos deles não têm acesso durante o restante do ano, incentivando o "abandono" das atividades cotidianas, sem a responsabilidade de horários, transporte para o trabalho, deixando o tempo livre para seus gostos pessoais; aos hóspedes com filhos são reservadas atividades para que não "incomodem" os pais, tais como descobrir o contato sensorial com as artes aplicadas da cerâmica e tecelagem, degustação da cozinha local, "caminhar" à altura e entre as copas das árvores com tirolesas e arborismo, locais que oferecem sons da natureza e podem aguçar o olfato, experiências táteis com a natureza; a ausência da natureza na vida contemporânea fez o retorno a ela uma "pulsão" explorada pelos tours operators e promotores do Club Med. O mote ambiental também fez surgir os bangalôs e os chalés em meio à natureza, muitas vezes arranjados espacialmente a reconstituírem valores sociais comunitários como essência da experiência humana. De maneira geral, esses meios de hospedagem "restauram" os hóspedes com o mínimo de obrigações e com o máximo de escolhas (DIAS, 1990). 
Os hotéis do tipo internacional podem apresentar uma série de atividades inusitadas perante o cotidiano dos códigos da residência: health club, boite, cabaret, piscina, sauna, fisioterapia, ginásio de esportes, quadras e pistas de cooper (DIAS, 1990).

E há uma série de outros hotéis inusitados como evocativos de emoção: antigos silos de aveia redondos podem ser fruídos como quartos de dormir no Hilton Inn da Quaker Square, em Akron, Ohio, EUA. Pode-se passar a noite em uma suíte em formato de um carro Pullman ou um vagão de trem na End of the Line Vacation Station, em Lake Geneve, Wisconsin, EUA. Antigas salas de aula (com lousa, mapas e giz) são agora tratadas como unidades habitacionais para hóspedes que querem reviver a "escola" no $A B C$ Country Inn, Buckingham, Iowa, EUA (CHON, 2003). Pode-se vivenciar um modo de vida rural junto à natureza por meio dos resorts fazenda nos EUA; alguns transportam as pessoas em carroças de época e oferecem a oportunidade de interação com bezerros, gastronomia de época e regional e uma noite de descanso em sacos de dormir (CHON, 2003).

A região da Grande Barreira de Corais na Austrália possui um hotel subaquático onde os hóspedes desfrutam das exclusivas paisagens do mundo submarino (WALKER, 2002).

Pode-se elencar ainda um tipo de turismo, chamado por alguns pesquisadores de "turismo hoteleiro", onde os hóspedes procuram vivenciar situações inusitadas dentro das dependências de um hotel. Assim se dá, por exemplo, com hóspedes que querem pernoitar onde pessoas famosas, importantes e ricas se hospedaram ou até moraram. É o caso de algumas suítes reformadas do Hotel Ritz Paris: suíte Chopin, suíte Chanel (com objetos da antiga moradora Coco Chanel), suíte Windsor, suíte Proust e suíte Cocteau (DIAS, 2002).

Cita-se a praia de Weymouth, em Dorset, Reino Unido, que abriga o primeiro hotel de areia habitável do mundo. Também o Hotel Amam I Khas, em Rajasthan, na Índia, pode proporcionar a vivência de tendas para pernoite, tal qual se faziam no passado quanto às características de migração dessa população local (EXTREMES HOTELS, 2007). O Ingloo Villages, na Suíça, pode proporcionar a pernoite em um simulacro de iglu (EXTREMES HOTELS, 2007), bem como o White Pod Hotel, também na Suíça, configura-se como uma "bola" habitável internamente em meio à neve; o Tron Themed Hotel e o Ice Hotel, na Suécia, possuem as unidades habitacionais e o mobiliário feito em gelo. Na Lapônia finlandesa, encontra-se o Hotel \& Igloo Kakslauttanen, com unidades habitacionais em formato de iglus (CONHEÇA..., 2013). O Underwater Cottage na Suécia é um meio de hospedagem que oferece unidade habitacional subaquática (EXTREMES HOTELS, 2007). Assim como o Jules Undersea Lodge, na Key Largo, Flórida, EUA, ou o Poseidon Undersea Resort, nas Ilhas Fiji (CONHEÇA..., 2013).

Ainda exemplificando, o Tipi Village nos EUA apresenta tendas para se dormir tais quais as encontradas entre os índios tipi da região onde se implanta o hotel (EXTREMES HOTELS, 2007). O Astro Hotel no Chile possui cabanas dotadas com alta tecnologia, bem como um potente telescópio em cada unidade habitacional, que proporciona a observação celeste enquanto experiência inusitada (EXTREMES HOTELS, 2007). A Earthship Rental proporciona a experiência dentro de um meio de hospedagem de uma casa totalmente sustentável e com tudo aquilo que necessitam os hóspedes de maneira autônoma (EXTREMES HOTELS, 2007).

A TreeHouse Hotel é "literalmente" uma casa na árvore, e também uma unidade habitacional de hotel (EXTREMES HOTELS, 2007), da mesma forma que o Treehotel em Harads, na Suécia (CONHEÇA..., 2013). O Harbour Crane na Holanda é um hotel em zona portuária, dentro de uma grua como exemplar 
da era industrial; oferece vista para o mar Wadden, para o porto e para o centro histórico de Harlingen; os hóspedes podem pilotar a grua, o que para muitos significa um sonho de infância (EXTREMES HOTELS, 2007).

Bem diferente também são os hotéis em meios de transporte: o Jumbo Stay Hostel, no Aeroporto de Estocolmo, um meio de hospedagem dentro de um Boing 747 (CONHEÇA..., 2013). A empresa turística Oliver's Travel promove estadas em um submarino nos mares do Caribe (CONHEÇA..., 2013). O Koh Samui Imperial Boat House, na Tailândia, possui unidades habitacionais construídas em antigos barcos de transporte de arroz, próprios da região onde se implantam (CONHEÇA..., 2013). Nos EUA, o The Shady Dell oferece unidades habitacionais em trailers de alumínio da década de 1950 (CONHEÇA..., 2013). Nos EUA o Northem Rail Traincar Suites se apropria de vagões de trens restaurados para fazer unidades habitacionais de hotel (CONHEÇA..., 2013). O Hotel V8, na Alemanha, possui as unidades habitacionais decoradas com motivos automobilísticos (CONHEÇA..., 2013).

O Prison Hostel na Eslovênia é um albergue que proporciona a experiência de estar preso, pois suas unidades habitacionais são as celas carcerárias do passado (EXTREMES HOTELS, 2007), bem como o Alcatraz Hotel, na Alemanha, e o Malmaison Oxford Castle, na Inglaterra (CONHEÇA..., 2013). Ou ainda o Jailhotel Lowengraben na Suíça ou Het Arresthuis na Holanda (PRESÍDIO..., 2013). O Quinta Real Zacatecas se apropria de uma antiga praça de touros mexicana do século XIX como hotel (CONHEÇA..., 2013). O Church Hotel na Holanda possui unidades habitacionais dentro de uma igreja monumental do século XV (EXTREMES HOTELS, 2007). O Pestana Convento do Carmo, em Salvador, BA, Brasil, apropria-se de um antigo convento proporcionando ao hóspede a experiência da clausura.

Seguindo a proposta, o Sewer-Pipe Hotel é uma unidade habitacional de hotel dentro de uma manilha para esgotos (EXTREMES HOTELS, 2007). Também como o Das Park Hotel, na Áustria (CONHEÇA..., 2013). O Gipsy Camp Hotel na Holanda possui autênticas caravanas de circo retomadas como unidades habitacionais de hotel (EXTREMES HOTELS, 2007). Na Malásia, o Seaventures Dive Resort pode proporcionar a experiência de se hospedar em uma plataforma de petróleo (CONHEÇA..., 2013). Na África do Sul, um hotel de luxo, o Emoya Luxury Hotel, promove aos seus hóspedes a experiência de vivenciar uma favela (CONHEÇA..., 2013). O hotel Im Wasserturm se instala em uma antiga torre que servia de reservatório de água na cidade de Colônia, na Alemanha (CONHEÇA..., 2013). O Hotel Farol Harlinger se apropria de um antigo farol (CONHEÇA..., 2013). Em Haya, na Holanda, duas cápsulas de sobrevivência que datam de 1972 com um diâmetro de 4,25 metros foram habilitadas como quartos de um hotel flutuante (EXTREMES HOTELS, 2007). Também como cápsulas em meio à natureza, encontra-se o Hotel Free Spirits Spheres, no Canadá. Da mesma forma, no Japão, há o Green Plaza Shinjuku Capsule Hotel (CONHEÇA..., 2013).

Referenciando a natureza, o hotel francês Attrap'Rêves se configura com unidades habitacionais transparentes, tendo, portanto, a natureza como parte da ambientação (CONHEÇA..., 2013). O Hotel Kelebek, na Turquia, possui unidades habitacionais escavadas em uma rocha natural, assim como o Gamirasu Cave Hotel, na Capadócia. Tal como o Kokopelli Cave Bed and Breakfast, nos EUA, que possui unidades habitacionais em cavernas. O Mine Hotel, na Suécia, possui unidades habitacionais em meio a uma mina de prata (CONHEÇA..., 2013).

Na Bolívia, o Hotel Palacio de Sal é construído e revestido em sal (CONHEÇA..., 2013). O Emirates Palace Hotel em Abu Dhabi reconstrói os ambientes palacianos daquela cultura local para seus hóspedes (CONHEÇA..., 2013). O Marina Bay Hotel, em Cingapura, apresenta uma piscina com vista inusitada 
para a cidade (CONHEÇA..., 2014). O Hotel Blue Laggon Geothermal Spa, na Islândia, possui piscinas com águas vulcânicas (CONHEÇA..., 2014). O Hotel Laggon Cristal, no Chile, possui uma piscina com 1 $\mathrm{km}$ de comprimento. Também no Chile, o Montaña Mágica Lodge se apresenta em forma de um vulcão em sua arquitetura, e expele água de seu cume, transformando-se em uma grande cascata (CONHEÇA..., 2014). Além dos exemplos citados ao longo do texto, muitos outros já surgiram enquanto este material estava sendo elaborado.

Pode-se interpretar em todos esses casos elencados acima o valor "fantasioso", "fora da realidade", do entretenimento ao extremo como alienação da sociedade. Porém, pode-se justificar que se trata (assumidamente) do simulacro (enquanto elemento "festivo" e nos termos de Jean Baudrillard) como código da dimensão do "tempo de e em férias"; muito ao contrário da simulação, que poderia "fantasiar" o cotidiano: "Para muitos a hospedagem é diversão [...] fuga da rotina (turismo cultural), novos conhecimentos [...]" (OTTO, 2011, p. 2). E ainda: "Um universo imaginário? Não, um novo mundo, identificado pela essência e pelas emoções” (OTTO, 2011, p. 4).

Para Yázigi (2000, p. 21), “[...] a arquitetura tem fortes ligações com nossas fantasias e imagens do mundo [...]" ao se referir aos meios de hospedagem. Ainda que se possa verificar que o tempo "fantasioso" é momentâneo dentro da expectativa das diárias no hotel.

E ainda se pode verificar em pequenos serviços da hotelaria, geralmente associados à oferta dos espaços hoteleiros, a condição de se ultrapassar o conceito de home way from home: camas separadas para casais de culturas em que assim o fazem; oferta de cardápios, canais de televisão, rádio, jornais e revistas do país de origem do hóspede; respeito às diferenças regionais internas de país de escala continental e tão diversa de culturas (caso do Brasil e EUA, por exemplo); flexibilidade para condições especiais de organização do espaço (crianças, idosos, portadores de necessidades especiais, doentes, obesos, diferentes etnias e biótipos quanto ao uso de mobiliários, rituais religiosos de diferentes hóspedes, entre outras) (WADA, 2003). Serviços em que os próprios hóspedes operam máquinas e equipamentos para seu melhor conforto, amparado pelo signo da singularidade do indivíduo; assim se pode elencar o Hotel Qbic Hip em Amsterdã, na Holanda, que tem como "mote" de oferta de serviços a frase "the best service is self-service" (SPOLON, 2011).

Todas essas vertentes da hotelaria também vieram para questionar a estandardização globalizante dos projetos de hotéis, pois muitos dos executivos que viajam incessantemente, com frequência perdiam a noção do lugar onde estavam, por acordarem em quartos como muitos outros e em outros lugares; os hotéis seguiam o modelo americano ou o europeu (OTTO, 2011).

\section{Emoção como personificação do espaço e dos serviços em meios de hospedagem}

Pode-se justificar a emoção pelos serviços e aspectos da ambiência personalizada de um hotel: "A emoção é um sentimento que continua sendo uma prerrogativa do ser humano. Muito importante nas prestações hoteleiras" (CASTELLI, 2000, p. 129).

Um bom exemplo disso é que nos atendimentos ligados à alimentação em um hotel, seja no restaurante como no serviço de quarto, nota-se a presença do hóspede (cliente) como parte do processo produtivo, pois é ele quem por vezes indica os ingredientes, os modos de se preparar o alimento; ainda que muitos 
hotéis possuam um serviço de cozinha internacional, a qual tais condições são sempre únicas. De sorte que, diferentemente de um processo produtivo como o de automóveis, há uma interação personificada do produto e até do serviço prestado.

Os resorts contemporâneos reforçam a ideia de que o hotel não é apenas o local para a restauração, mas pode ser o suporte para o entretenimento e diversão, daí o ideal da animação, porém, segundo Dias (1990), não se trata de uma animação passiva na fruição de um espetáculo (por exemplo), mas de uma animação com a participação ativa do hóspede.

Outro exemplo: os hotéis abeku ou "hotéis do amor" no Japão, dotados de ambiência palaciana, referenciam chalés alpinos e com jardins internos; possuem uma parafernália eletroeletrônica que enfatiza o bem-estar de seus hóspedes com vários canais de televisão, som, vídeo e sauna dentro da unidade habitacional, configurando um refúgio particular para casais. Deve-se notar que a alta densidade populacional do Japão e o uso de paredes muito finas e biombos (em razão de terremotos) resultaram em moradias muito próximas e que por vezes tiram a privacidade dos casais; daí o sucesso dos hotéis abeku contando com uma rede de aproximadamente 20 mil estabelecimentos no Japão (CHON, 2003).

Alguns hotéis podem proporcionar emoção a partir da fruição da natureza. Caso exemplar é o Treetops Hotel em meio a uma reserva de animais selvagens, dentro do parque Treetops, no Quênia, África. Ali há uma percepção inusitada para o hóspede que pode "caminhar" entre a copa das árvores, bem como observar as aves selvagens que se aproximam para beber água em virtude de um grande lago junto aos hóspedes (WALKER, 2002).

A oferta de serviços e lojas também pode conferir um fator emotivo dentro do hotel: o consumo pode conferir distinção social e passa a ser um comportamento entre as ações praticadas em um meio de hospedagem (LEHN, 2004).

Uma categoria que vem se sistematizando com o tempo são os chamados "hotéis boutique", provavelmente termo criado pelo empresário americano Ian Scharager. Eles integram diversos signos de emoção através do espaço: poucos quartos, decoração preciosa e projeto arquitetônico assinado por um arquiteto de renome internacional (PETROCCHI, 2002).

Até mesmo o desenho e escolha do mobiliário de um hotel têm funções identitárias para com a arquitetura do hotel, a região em que está localizado e sua época de construção (ANDRADE; BRITO; JORGE; 2000); além do signo de exclusividade para com o hotel, o mobiliário pode remeter à lembrança de experiências pretéritas e assim ocasionar um valor emotivo.

Outra condição que se pode evidenciar em serviços e espaços de hotéis é a introdução de animais como fator de fruição; assim, por exemplo, pode-se elencar o Jefferson-Sheraton Hotel inaugurado em 1895, o qual possuía jacarés que mergulhavam vez por outra em lagoas decorativas (DONZEL, 1989). O Hotel Peabody colocou em 1930 patos que seguiam para lagoas artificiais acompanhados por música e sobre um tapete vermelho (DONZEL, 1989), ou o voo de patos em muitos hotéis da Disney, com o intuito de entretenimento por todo o período do dia para o norte-americano em férias. 


\section{Considerações finais}

Tanto na ideia de "reprodução do lar" como na do "além do home way from home" há uma preocupação com a ação hospitaleira. Pode-se sintetizar uma nova fase atual da hotelaria pelos signos dos espaços como interatividade e capaz de despertar estímulos - daí então o valor emotivo.

Fato é que os hotéis contemporâneos conseguem ofertar uma gama de programas arquitetônicos, funções, usos e serviços que não só são privilégios para turistas, mas também para cidadãos (SPOLON, 2011). Mesmo porque, ao se inserir na malha urbana, o edifício hoteleiro interfere na morfologia, uso e função da estrutura da cidade (SPOLON, 2011). Por isso, o ingrediente emotivo que vem sendo enfatizado nas arquiteturas de meios de hospedagem pode ser um referencial para a arquitetura civil dos moradores e da cidade, haja vista uma diversidade de tipologias e classificações de meios de hospedagem, que por vezes se confundem entre si, e até se confundem com habitações próprias dos cidadãos. Para Polizel (2006), o fato de se querer classificar os meios de hospedagem é um signo que denota o compromisso que o hotel tem em oferecer hospitalidade, uma vez que tal classificação pode indiciar as condições dos espaços e serviços que serão ofertados.

De sorte que, à guisa de uma conclusão, a arquitetura contemporânea, em sua generalidade, pode se apoiar em exemplificações da arquitetura hoteleira, como que um trocadilho de home way from home para hotel way from home.

Deve-se verificar ainda que o fator empírico da hotelaria é que tem demonstrado seu papel para a construção de categorias de análise para a própria arquitetura contemporânea, uma vez que "Em termos conceituais, há pouca coisa publicada [...]" (SPOLON, 2011). Se a hotelaria então inclui valores de hospitalidade, há, então, um novo desdobramento para se pensar em outras categorias de hospitalidade a partir dos fenômenos empíricos da arquitetura hoteleira contemporânea - uma hospitalidade que "provoca" a mente e é capaz se instigar associações e cognições por meio da linguagem do espaço, da interação social e dos novos equipamentos de uma era eletroeletrônica. A hospitalidade passa então não só a um valor por seus signos de conforto, bem-estar, deleite e ócio recreativo, mas inclui agora um ócio "criativo" (nos termos de Domenico de Masi) e ativador de exercícios da e com a mente.

O Turismo então deve reconhecer o valor da hotelaria como dado intrínseco: só há turismo se houver o deslocamento do indivíduo, e muito provavelmente o meio de hospedagem como suporte para tanto - e eis que tal hotelaria hoje passou a ser também não somente suporte para o destino, mas, em muitos casos, o próprio destino. A viagem e o escapismo como "sonho" onde o hotel é parte dele.

\section{Referências}

CASTELLI, G. Excelência em Hotelaria: uma abordagem prática. Rio de Janeiro: Editora Qualitymark, 2000.

CHON, K. S. Hospitalidade: conceitos e aplicações. São Paulo: Pioneira Thomson Learning, 2003.

CONHEÇA os hotéis mais esquisitos e curiosos do mundo. 2013. Disponível em: 〈http://noticias.bol. uol.com.br/fotos/entretenimento/2013/12/16/conheca-os-hoteis-mais-esquisitos-e-curiosos-domundo.htm?fotoNav=1\#fotoNav=69>. Acesso em: 08 mar. 2016. 
CONHEÇA piscinas incríveis. 2014. Disponível em: 〈http://noticias.bol.uol.com.br/fotos/ entretenimento $/ 2014 / 05 / 19 /$ conheca-piscinas-incriveis.htm?fotoNav=1\#fotoNav=11. Acesso em: 08 mar. 2016.

DIAS, C. M. de M. Home away from home. Dissertação (Mestrado) - Programa de Pós-graduação em Ciências da Comunicação. Escola de Comunicações e Artes (ECA) da Universidade de São Paulo (USP). São Paulo, 1990.

(Org.). Hospitalidade: reflexões e perspectivas. Barueri: Manole, 2002.

DONZEL, C. Grand American Hotels. New York: The Vendomi Press, 1989.

EXTREMES Hotels. Antwerp: Tectum Publishers, 2007.

KOGA, É. S. Empreendimentos hoteleiros dentro de unidades de conservação. Trabalho de Conclusão de Curso. Curso de Turismo e Hotelaria da Escola de Comunicação e Artes (ECA) da Universidade de São Paulo (USP). São Paulo, 2002.

LEHN, S. A fruição do lazer em resorts: aspectos simbólicos imaginários que possibilitam e mantêm a modalidade de prestação de serviços. Dissertação (Mestrado) - Pós-graduação em Turismo e Hotelaria da Universidade do Vale do Itajaí. Balneário Camboriú, SC, 2004.

OTTO, G. A nova era da arquitetura e decoração dos hotéis. Disponível em: 〈http://www.hloft.com.br/ nova-era-da-arquitetura-e-decoracao-dos-hoteis/>. Acesso em: 08 mar. 2016.

PETROCCHI, M. Hotelaria: planejamento e gestão. São Paulo: Futura, 2002.

POLIZEL, H. H. Sistema de classificação de meios de hospedagem por qualidade: um estudo exploratório descritivo. Dissertação (Mestrado) - Programa de Mestrado em Hospitalidade da Universidade Anhembi-Morumbi (UAM). São Paulo, 2006.

PRESÍDIO vira hotel de luxo na Holanda: hóspedes dormem nas celas. 2013. Disponível em: 〈https:// arcoweb.com.br/noticias/noticias/presidio-vira-hotel-luxo-holanda-hospedes-dormem-nas-celas >. Acesso em: 08 mar. 2016.

SPOLON, A. P. G. Hotelaria, Cidade e Capital. Tese (Doutorado) - Faculdade de Arquitetura e Urbanismo (FAU) da Universidade de São Paulo (USP). São Paulo, 2011.

SYKES, A. K. (Org.). 0 campo ampliado da arquitetura: antologia teórica 1993-2009. São Paulo: Cosac Naify, 2013.

WADA, E. K. Reflexões de uma aprendiz da hospitalidade. In: DENCKER, A. de F. M.; BUENO, M. S. (Org.). Hospitalidade: cenários e oportunidades. São Paulo: Pioneira Thomson Learning, 2003.

WALKER, J. R. Introdução à Hospitalidade. Barueri: Manole, 2002.

YÁZIGI, E. A pequena hotelaria e o entorno municipal: guia de montagem e administração. São Paulo: Contexto, 2000. 